\title{
Alcaligenes ruhlandii (Packer and Vishniac) comb. nov., a Peritrichous Hydrogen Bacterium Previously Assigned to Pseudomonas
}

\author{
MICHEL ARAGNO ${ }^{1}$ AND HANS G. SCHLEGEL \\ Institut für Mikrobiologie der Universität und der Gesellschaft für Strahlen- und Umweltforschung mbH, \\ Munich, Göttingen, Federal Republic of Germany
}

\begin{abstract}
ATCC 15749, a hydrogen bacterium placed in Hydrogenomonas ruhlandii by Packer and Vishniac (1955) and then transferred to Pseudomonas by Davis et al. (1969), is peritrichous and belongs in the genus Alcaligenes. ATCC 15749 is the type strain of $H$. ruhlandii Packer and Vishniac, and by reason of its transfer to the genus Alcaligenes, the name of the species becomes Alcaligenes ruhlandii (Packer and Vishniac) comb. nov. It differs from Alcaligenes eutrophus by lacking the ability both to use aromatic compounds and to denitrify and by possessing broad, sheathed flagella.
\end{abstract}

Packer and Vishniac (5) described a motile, colorless hydrogen bacterium for which they proposed the name Hydrogenomonas ruhlandii. These authors did not describe the mode of flagellation of this organism. Later, Davis et al. (1) rejected the genus Hydrogenomonas and transferred the polarly flagellated hydrogenomonads to Pseudomonas and the peritrichous ones to Alcaligenes. They transferred $H$. ruhlandii to Pseudomonas, implying that it was polarly flagellated. Neither in the publications of Davis et al. $(1,2)$ nor in D. H. Davis' Ph.D. thesis (University of California, Berkeley, 1967) did they mention their observations on the flagellation of this species. Because $H$. ruhlandii resembles Alcaligenes eutrophus, another hydrogen bacterium, it was evident that the mode of insertion of the flagella of $H$. ruhlandii had to be determined before the question of the taxonomic placement of this organism could be resolved.

A culture of ATCC 15749 (=DSM 653) was obtained from the Deutsche Sammlung von Mikroorganismen; confirmation of the identity of this culture was then made using a culture of this same strain recently obtained directly from the American Type Culture Collection.

Cells were grown in liquid culture or on nutrient agar plates; from these plates, a suspension was obtained by gently shaking with 50 $\mathrm{mM}$ phosphate buffer. Cells were stained without fixation as described by Valentine et al. (6) using, however, uranyl acetate (pH 5.0,2\%) or potassium phosphotungstate $(\mathrm{pH} 7.0,2 \%)$ dis-

\footnotetext{
${ }^{1}$ Present address: Laboratoire de Microbiologie, Institut de Botanique, CH-2000 Neuchâtel 7, Switzerland.
}

solved in water. Electron micrographs were taken with a Philips EM 301 instrument.

The cells of Pseudomonas ruhlandii ATCC 15749 were found to be peritrichous with 2 to 10 flagella per cell (Fig. 1). The number of flagella depended on the substrate and on the age of the culture; it was maximal in cells obtained from cultures growing on nutrient agar. The flagella were about 17 to $18 \mathrm{~nm}$ in diameter and were distinctly sheathed (Fig. 2). The sheath did not extend over the basal hook.

On the basis of its clearly peritrichous cells, strain ATCC 15749 must be excluded from the genus Pseudomonas. As noted elsewhere $(2,5)$, this strain is strictly aerobic, with a respiratory metabolism, and is a hydrogen-oxidizing facultative autotroph. All of these features agree with the emended description of the genus $\mathrm{Al}$ caligenes by Hendrie et al. (4). It is thus appropriate to include this species in the genus Alcaligenes.

With respect to many of its properties, strain ATCC 15749 resembles strains of A. eutrophus. The substrate utilization spectra (2) of these organisms are very similar. Both are facultatively autotrophic, nonpigmented, hydrogen bacteria. Both possess two types of hydrogenases: a membrane-bound enzyme, which does not react with nicotinamide adenine dinucleotide (NAD), and an NAD-specific soluble hydrogen-dehydrogenase $(3,7)$. However, some important differences remain. For example, strain ATCC 15749 differs from A. eutrophus in its inability to use aromatic compounds such as phenol, benzoate, and $p$-hydroxy-benzoate (2). Moreover, its flagella are sheathed, contrary to those of A. eutrophus, which have a smaller 


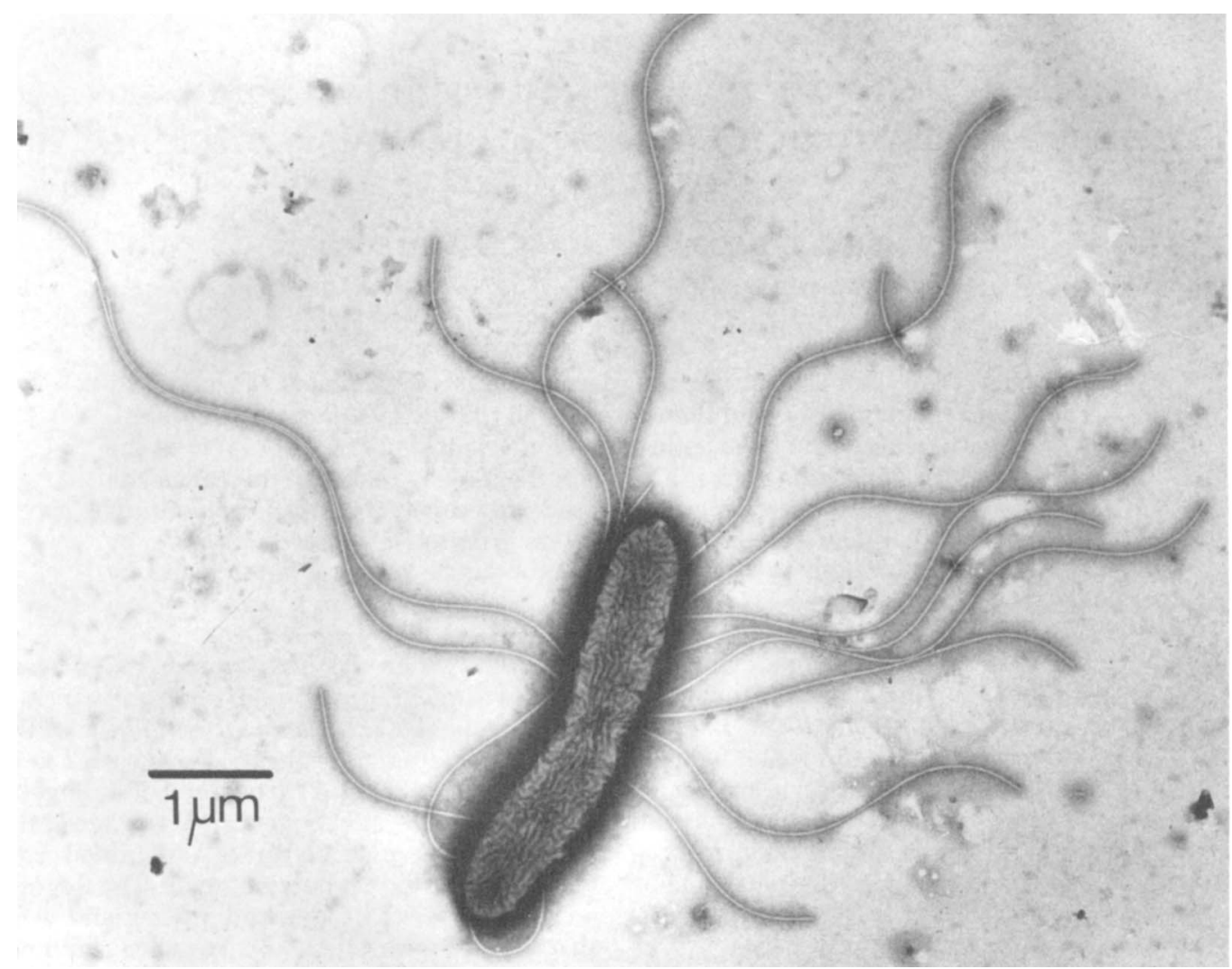

Fig. 1. Dividing cell of Alcaligenes ruhlandii from an 18-h-old culture on nutrient agar (Difco). Negatively stained with $2 \%$ potassium phosphotungstate.

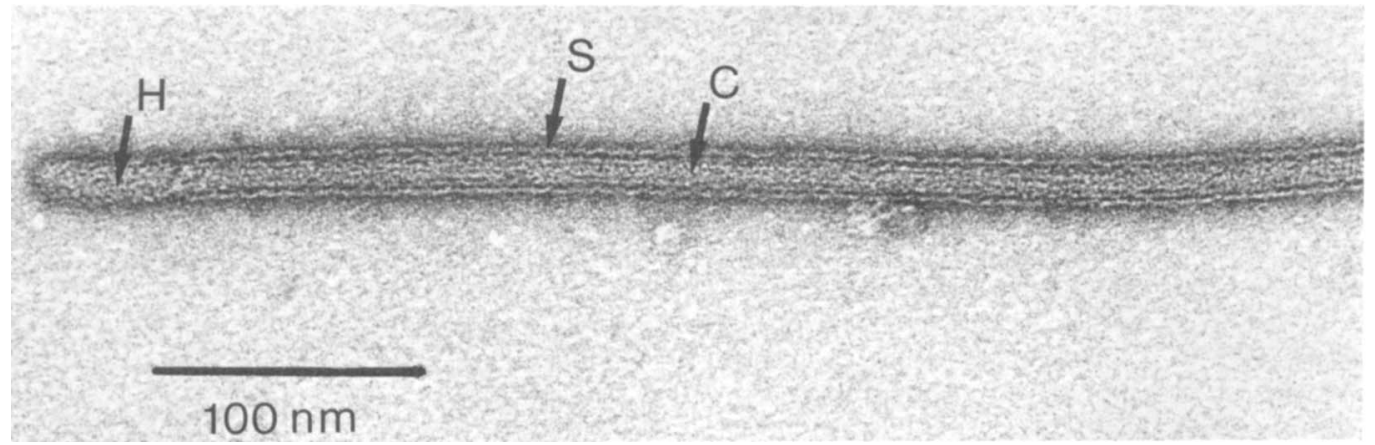

Fig. 2. Fine structure of the proximal end of an Alcaligenes ruhlandii flagellum. Abbreviations: $H$, hook; $S$, sheath; $C$, central core. Negatively stained with $2 \%$ uranyl acetate.

diameter and a distinct spiral structure (A. Walther-Mauruschat, unpublished observation). We propose, therefore, to transfer strain ATCC 15749 , the type strain of $H$. ruhlandii, to the genus Alcaligenes. By reason of this transfer, the name of this organism becomes Alcali- genes ruhlandii (Packer and Vishniac) comb. nov.

\section{REPRINT REQUESTS}

Address reprint requests to: Prof. Dr. H. G. Schlegel, Institut für Mikrobiologie, Grisebachstr. 8, 3400 Göttingen, Federal Republic of Germany. 


\section{LITERATURE CITED}

1. Davis, D. H., M. Doudoroff, R. Y. Stanier, and M. Mandel. 1969. Proposal to reject the genus Hydrogenomonas. Taxonomic implications. Int. J. Syst. Bacteriol. 19:375-390.

2. Davis, D. H., R. Y. Stanier, M. Doudoroff, and M. Mandel. 1970. Taxonomic studies on some Gram negative polarly flagellated "hydrogen bacteria" and related species. Arch. Mikrobiol. 70:1-13.

3. Eberhardt, U. 1966. Über das wasserstoffaktivierende System von Hydrogenomonas H 16. I. Verteilung der Hydrogenase-Aktivität auf zwei Zellfraktionen. Arch. Mikrobiol. 53:288-302.

4. Hendrie, M. S., A. J. Holding, and J. M. Shewan. 1974. Emended descriptions of the genus Alcaligenes and of
Alcaligenes faecalis and proposal that the generic name Achromobacter be rejected: status of the named species of Alcaligenes and Achromobacter. Request for an opinion. Int. J. Syst. Bacteriol. 24:534-550.

5. Packer, L., and W. Vishniac. 1955. Chemosynthetic fixation of carbon dioxide and characteristics of hydrogenases in resting cell suspensions of Hydrogenomonas ruhlandii nov. spec. J. Bacteriol. 70:216-233.

6. Valentine, R. C., B. M. Shapiro, and E. R. Stadtman. 1968. Regulation of glutamine synthetase. XII. Electron microscopy of the enzyme from $E$. coli. Biochemistry 7:2143-2152.

7. Vishniac, W., and P. A. Trudinger. 1962. Carbon dioxide fixation and substrate oxidation in the chemosynthetic sulfur and hydrogen bacteria. Bacteriol. Rev. 26:168-175. 